\title{
PENGARUH KAWIN PERTAMA PASCAPARTUM SAPI POTONG TERHADAP ANGKA KEBUNTINGAN DI KODYA PADANG
}

\section{Zaituni Udin \\ INTISARI}

Penelitian ini bertujuan untuk menentukan pengaruh kawin pertama pascapartum terhadap angka kebuntingan dan angka perkawinan per kebuntingan serta untuk mendapatkan kawin pertama pascapartum yang terbaik pada sapi yang di IB di Kodya Padang. Penelitian dilakukan secara eksperimen dengan 4 tingkat jarak kawin pertama pascapartum dengan 4 Pos Inseminasi Buatan (PIB) sebagai ulangan atau kelompok yaitu PIB Nanggalo, Pauh, Kuranji, dan Koto Tangah. Jumlah sapi yang digunakan untuk setiap PIB adalah 60 ekor dengan jumlah keseluruhan adalah 240 ekor. Rancangan yang digunakan pada penelitian ini adalah rancangan acak kelompok (RAK). Hasil penelitian ini menunjukan bahwa rataan angka kebuntingan (CR) pada jarak kawin pertama pascapartum untuk perlakuan A (60 hari); B (90 hari); C (120 hari) dan D (150 hari) adalah 51,66; 63,$33 ; 64,99$ dan $65,00 \%$ secara berturut-turut. Rataan keseluruhan angka kebuntingan (CR) pada penelitian ini adalah $61,24 \%$. Rataan angka perkawinan per kebuntingan (S/C) untuk perlakuan A (60 hari); $\mathrm{B}(90$ hari); $\mathrm{C}$ (120 hari) dan D (150 hari) adalah 1,61; 1,49;1,48; dan 1,54 secara berturut-turut. Rataan keseluruhan keseluruhan angka perkawinan per kebuntingan adalah 1,53. Hasil analisa statistik memperlihatkan bahwa jarak kawin pertama pascapartum tidak berbeda nyata terhadap angka kebuntingan (CR) dan angka perkawinan per kebuntingan (S/C). Dari hasil penelitian ini dapat disimpulkan bahwa jarak kawin pertama pascapartum yang terbaik pada sapi yang di inseminasi buatan di Kodya Padang adalah 90 hari pascapartum (perlakuan B).

(Kata kunci: Inseminasi Buatan, Pascapartum, Angka kebuntingan, Serviceper Conception).

Buletin Peternakan 29 (4) : 156 - 162, 2005

${ }^{1}$ Fakultas Peternakan Universitas Andalas, Padang. 


\title{
EFFECTS OF INTERVAL FIRST SERVICE POSTPARTUM OF BEEF CATTLE ON CONCEPTION RATE IN PADANG
}

\begin{abstract}
The objective of this research to determine the effect of first service after calving to Conception Rate $(C R)$ and the best service preconception (S/C) of beef cattle underwent AI at the city of Padang. This research applied 4 levels of interval first service after calving which were treatment $\mathrm{A}=60$ days after calving; $\mathrm{B}=90$ days after calving; $\mathrm{C}=120$ days after calving and $\mathrm{D}=150$ after calving. The number of cattle postpartum were 240 heads in four AI centers in Padang. The experiment was designed as a randomized block design (RBD) with four blocks. The result of this experiment showed that the average of conception rate in the four interval first service after calving A;B;C; and D were $51.66 ; 63.33 ; 64.99$ and $65.00 \%$, respectively. Overall average of conception rate (CR) was 61,24 percent. Average of service preconception (S/C) in treatment A;B;C; and D were $1.61 ; 1.49 ; 1.48$ and 1.54 , respectively. Overall average of service per conception was $1.53 \%$. The effect of interval first service after calving to conception rate and service per conception was not significant and the best conception rate and service per conception were those underwent interval first service 90 days after calving.
\end{abstract}

(Key words: Artificial Insemination, Postpartum, Conception rate, Service Preconception).

\section{Pendahuluan}

Program Inseminasi Buatan (IB) diterapkan dalam rangka meningkatkan mutu dan populasi ternak sapi rakyat di Indonesia. Inseminasi Buatan ini dilakukan dengan menggunakan semen beku yang berasal dari sapi jantan unggul. Akhir-akhir ini telah dicoba pula dengan penerapan program Transfer Embrio (TE) baik menggunakan embrio segar maupun embrio beku pada daerah yang terbatas maupun pada pusat-pusat penelitian maupun pada perguruan tinggi. Walaupun demikian peningkatan mutu maupun populasi ternak sapi belum optimal, ini tercermin dari penampilan reproduksi yang masih rendah yaitu selang beranak untuk sapi perah dan potong adalah masih panjang dari 16 bulan dengan angka konsepsi berkisar $62 \%$ dan $45 \%$ untuk sapi perah dan sapi potong secara berturut-turut.

Rendahnya produktivitas ternak sapi antara lain disebabkan kegagalan reproduksi yang bersifat sementara seperti tatalaksana reproduksi yang kurang baik, disamping faktor ternak itu sendiri. Menurut Partodihardjo (1992) bahwa kegagalan reproduksi dibedakan atas sterilitas dan infertilitas. Sterilitas adalah kegagalan yang bersifat permanen misalnya karena radang menahun pada saluran reproduksi, dan infertilitas adalah bersifat sementara misalnya karena manajemen atau tatalaksana perkawinan yang tidak baik.

Kawin pertama pascapartum merupakan penampilan reproduksi yang mencerminkan efisiensi reproduksi ternak yang baik. Apabila pengontrolan berahi dan pengaturan perkawinan pascapartum dengan baik maka akan meningkatkan jumlah anak yang lahir dan performan ternak sapi yang baik. Untuk meningkatkan angka kebuntingan dan jumlah anak sapi yang lahir dari hasil IB maka perlu dilakukan pengaturan perkawinan sapi-sapi pascapartum dengan jalan memperpendek kawin pertama pascapartum.

Di Kodya Padang umumnya peternak mengawinkan sapi secara inseminasi butan, namun pelaksanaan IB tidak diikuti dengan tatalaksana perkawinan sapi yang teratur, sehingga tujuan IB belum dapat dicapai. Pada peternakan rakyat tatalaksana reproduksi sapi pascapartum belum diperhatikan dengan baik, sehingga peternak tidak tahu kapan sebaiknya untuk mengawinkan sapi-sapi pascapartum. Menurut Alexander et al. (1998) bahwa rendahnya tingkat fertilitas ternak mempunyai korelasi dengan tatalaksana, deteksi berahi, 
waktu pelayanan IB, tehnisi dan pejantan yang digunakan.

Berdasarkan masalah yang diuraikan di atas maka dilakukan penelitian untuk mengetahui pengaruh jarak kawin pertama pascapartum terhadap angka kebuntingan dan kawin pertama dan untuk mendapatkan jarak kawin pertama pascapartum yang terbaik pada peternakan rakyat.

\section{Materi dan Metode}

Penelitian ini menggunakan induk sapi pascapartum yang menjadi akseptor IB pada 4 PIB (Pos Inseminasi Buatan) di Kodya Padang. Setiap PIB diambil 60 ekor sapi pascapartum dengan jumlah keseluruhan sapi yang digunakan adalah 240 ekor. Semen yang digunakan untuk mengawinkan sapi adalah semen beku dari sapi Simmental.

Penelitian ini dilakukan secara eksperimen dengan menggunakan 4 tingkat jarak kawin pertama pascapartum sebagai perlakuan yaitu:

$$
\begin{aligned}
& A=60 \text { hari pascapartum } \\
& B=90 \text { hari pascapartum } \\
& C=120 \text { hari pascapartum } \\
& D=150 \text { hari pascapartum }
\end{aligned}
$$

Masing-masing perlakuan terdiri dari 15 ekor sapi pascapartum dan empat kelompok PIB sebagai uiangan (Nanggalo, Pauh, Kuranji, dan Koto Tangah). Pemilihan sampel berdasarkan catatan pada setiap PIB dan melihat langsung ke lapangan dan sesuai dengan kriteria yang ditetapkan. Untuk mendapatkan jarak kawin pertama pascapartum dengan menghitung tanggal beranak sampai IB pertama dilakukan.

Parameter yang diukur adalah angka kebuntingan (CR) dan angka perkawinan per kebuntingan (S/C).

Data yang didapatkan pada penelitian ini dianalisa dengan menggunakan analisa sidik ragam dalam rancangan acak kelompok menurut Steel dan Torrie (1989).

\section{Hasil dan Pembahasan}

\section{Angka Kebuntingan (Conception Rate $=$} CR). Rataan angka kebuntingan (CR) pada penelitian ini pada empat tingkat jarak kawin pertama pascapartum di empat PIB di Kodya Padang dapat dilihat pada Tabel 1. Hasil penelitian menunjukan bahwa semakin tinggi angka kebuntingan (CR) maka semakin panjang jarak kawin pertama pascapartum. Rataan keseluruhan angka kebuntingan pada penelitian ini adalah $61,25 \%$.

Tabel 1. Rataan angka kebuntingan $(C R=\%)$ pada empat tingkat jarak kawin pertama pascapartum di empat PIB Kodya Padang. (Average of conception rate $(C R=\%)$ in four level of first service after post partum at AI center in Padang)

\begin{tabular}{lccccc}
\hline POS IB (AI centre) & \multicolumn{3}{c}{ Jarak kawin pertama pascapartum (hari) } & \multicolumn{2}{c}{$\begin{array}{c}\text { Rataan (\%) } \\
\text { (Interval first service postpartum) }\end{array}$} \\
& A & B & C & D & \\
\hline Nanggalo & 44,66 & 66,66 & 66,66 & 60,00 & 59,99 \\
Pauh & 53,33 & 66,66 & 60,00 & 60,00 & 59,99 \\
Kuranji & 53,33 & 60,00 & 60,00 & 80,00 & 63,33 \\
Koto Tangah & 53,33 & 60,00 & 73,33 & 60,00 & 61,66 \\
$\quad$ Rataan (Average) & 51,66 & 63,33 & 64.99 & 65,00 & 61,25 \\
\hline
\end{tabular}

A: 60 hari pascapartum ( 60 days postpartum); B : 90 hari pascapartum ( 90 days postpartum); C: 120 hari pascapartum (120 days postpartum); D : 150 hari pascapartum (150 days postpartum). 
Tabel 2. Rataan angka perkawinan per kebuntingan (S/C) pada empat tingkat jarak kawin pertama pascapartum sapi di empat PIB di Kodya Padang. (Average on service per conception $=S / C$ on four level of interval first service after post partum of cattle at 4 AI centre in Padang)

\begin{tabular}{|c|c|c|c|c|c|}
\hline \multirow[t]{2}{*}{ Pos IB (AI centre) } & \multicolumn{4}{|c|}{$\begin{array}{l}\text { Jarak kawin pertama pascapartum (hari) } \\
\text { (Interval first service postpartum) (day) }\end{array}$} & \multirow[t]{2}{*}{$\begin{array}{c}\text { Rataan } \\
\text { (Average) }\end{array}$} \\
\hline & $\mathrm{A}$ & $\mathrm{B}$ & C & D & \\
\hline Nanggalo & 1,73 & 1,60 & 1,40 & 1,66 & 1,59 \\
\hline Pauh & 1,60 & 1,46 & 1,53 & 1,60 & 1,54 \\
\hline Kuranji & 1,60 & 1,40 & 1,60 & 1,40 & 1,50 \\
\hline Koto Tangah & 1,53 & 1,53 & 1,40 & 1,53 & 1,49 \\
\hline Rataan (Average) & 1,61 & 1,49 & 1,48 & 1,54 & 1,53 \\
\hline
\end{tabular}

A: 60 hari pascapartum ( 60 days postpartum); B : 90 hari pascapartum ( 90 days postpartum); C : 120 hari pascapartum (120 days postpartum); $\mathrm{D}: 50$ hari pascapartum (150 days postpartum).

Berdasarkan perhitungan statistik dengan menggunakan analisa ragam didapatkan bahwa jarak kawin pertama pascapartum tidak berbeda nyata $(P>0.05)$. Ini berarti bahwa dengan memperpanjang jarak kawin pertama pascapartum tidak memperbaiki angka kebuntingan (CR) Untuk itu untuk mendapatkan efisiensi reproduksi atau perfoman reproduksi yang baik dapat dilakukan dengan kawin pertama pascapatum yang tidak terlalu lama.

Hasil penelitian ini menunjukan bahwa pada perlakuan A (60 hari pascapartum) sudah merupakan yang baik dan ini sesuai dengan pendapat Partodihardjo (1992) dan Hafez (2000).

Diperkuat oleh Bearden dan Fuguay (1980) bahwa induk sapi tidak akan dikawinkan sampai berahi pertama 60 hari pascapartum. Hal ini berkaitan dengan involusi uteri yang sempuma, apabila terjadi berahi akan diikuti dengan ovulasi. Sehingga inseminasi yang dilakukan akan diikuti dengan terjadinya fertilisasi yang tinggi dan hasilnya akan sama dengan sapi yang dikawinkan dengan jarak kawin pertama pascapartum yang panjang. Ini sesuai dengan pendapat Morrow et al. (1969); Oltenacu et al. (1983); Spicer et al. (1986) dan Hafez (2000) bahwa sapi yang tertunda involusi uteri dan serviks pascapartum akan memperpanjang interval berahi pertama dan bunting. Untuk perlakuan B (90 hari pascapartum) sudah merupakan batas optimal dan belum terlambat. Sedangkan perlakuan C (120 hari pascapartum) dan perlakuan D (150 hari pascapartum) merupakan interval yang panjang dan sudah terlambat. Dari hasil penelitian ini menunjukan bahwa semakin pendek jarak kawin pertama pascapartum maka akan mendapatkan cepat menjadi bunting selanjutnya akan memperpendek jarak beranak. Pada hasil penelitian ini untuk perlakuan $A$ dan $B$ akan dapat mewujudkan jarak beranak (calving interval) yang optimal yaitu berkisar 12 sampai 13 bulan. Ini sesuai dengan pendapat Britt (1975) bahwa apabila interval inseminasi pertama sesudah beranak lebih lama maka calving interval akan menjadi lebih panjang. Dengan demikian sangat jelas bahwa kegagalan reproduksi dapat disebabkan oleh tatalaksana yang tidak terkontrol dan kurang baik. Oleh karena itu perlu dilakukan pengontrolan dan pengaturan sapisapi pascapartum dalam kawin pertama pascapartum. Ini sesuai dengan pendapat Bamualim et al. (1988) dan Partodihardjo (1992) bahwa pascapartum anestrus (ppa) yang panjang dianggap sebagai penyebab utama rendahnya kesuburan sapi diderah tropis.

Bervariasi angka kebuntingan pada penelitian ini disebabkan oleh jarak kawin pertama yang berbeda, disamping faktor yaitu lama menyusui dan faktor inseminator dalam melaksanakan pelayanan IB. Pada sapi yang di IB di lokasi penelitian pembatasan lama menyusui anak sapi belum pernah dilakukan, sehingga tingkat keberhasilan IB masih rendah. 
Ini sesuai dengan pendapat Abeygunawardena $e t$ al. (1995) dan Alexander et al. (1997) bahwa IB sudah diterima pada peternakan rakyat untuk sistim perkawinan dengan angka keberhasilan yang belum optimal yaitu angka kebuntingan kurang dari 60 persen. Menurut Laster et al. (1973) bahwa penyapihan akan meningkatkan angka konsepsi dan persentase sapi yang bunting tinggi didapatkan pada perkawinan yang lebih lama setelah partus.

Rataan angka kebuntingan pada penelitian ini hampir sama dengan yang dilaporkan oleh Soenarjo (1980) yaitu $66,74 \%$ tetapi lebih rendah dari yang didapatkan oleh West (1975) yaitu $70 \%$ dan Britt (1975) adalah $72 \%$. Namun lebih tinggi bila dibandingkan dengan penelitian yang dilakukan oleh Partiman (1982) mendapatkan angka kebuntingan $45,4 \%$ dan $43,1 \%$ di daerah Gunung Kidul dan Kulon Progo secara berturut-turit.

Berdasarkan hasil pembahasan diatas dapat disimpulkan bahwa jarak kawin pertama pascapartum tidak berpengaruh terhadap angka kebuntingan, sehingga semakin cepat kawin pertama pascapartum maka semakin tinggi fertilitas sapi yang di IB. Angka kebuntingan yang terbaik didapatkan pada perlakuan B ( 90 haripascapartum) yaitu $63,33 \%$.

\section{Angka Perkawinan per Kebuntingan} (Service per Conception $=\mathrm{S} / \mathrm{C}$ )

Rataan angka perkawinan per kebuntingan pada empat tingkat jarak kawin pertama pascapartum di empat Pos IB di Kodya Padang Japat dilihat pada Tabel 2. Angka perkawinan per kebuntingan berkisar dari $1,48-1,6$, dengan rataan secara keseluruhan pada penelitian ini adalah 1,53 .

Hasil perhitungan statistik dengan menggunakan analisa ragam memperlihatkan bahwa jarak kawin pertama pascapartum tidak berbeda nyata (P0.05) terhadap angka perkawinan per kebuntingan (S/C). Ini membuktikan bahwa dengan memperpanjang jarak kawin pertama pascapartum tidak memperbaiki angka perkawinan per kebuntingan.

Oleh karena itu tidak dianjurkan untuk menunda kawin pertama pascapartum pada ternak sapi rakyat dalam rangka meningkatkan fertilitas ternak sapi. Banyaknya kawin ulang sangat erat hubungannya dengan fertilitas, apabila angka perkawinan per kebuntingan tinggi maka semakin rendah fertilitas atau kesuburan ternak tersebut. Menurut Payne (1970) bahwa IB dapat dipakai untuk meningkatkan breeding efisiensi dan kesukaran yang timbul dalam hal reproduksi dapat diatasi. Namun demikian tidak selamanya IB dapat memberikan hasil yang baik dari kawin alam dalam faktor faktor yang menentukan breeding efficiency termasuk didalamnya jumlah perkawinan per kebuntingan.

Jarak kawin pertama pascapartum untuk perlakian B merupakan batas maksimal dan yang terbaik, karena belum terlambat dan tidak banyak kawin ulang. Sedangkan untuk perlakuan $\mathrm{C}$ angka perkawinan per kebuntingan sedikit lebih rendah dari perlakuan B tetapi sudah terlambat karena jarak kawin pertama pascapartum relatif panjang. Demikian juga untuk perlakuan $D$, walaupun lebih rendah dari perlakuan A tetapi jarak kawin pertama pascapartum sudah terlalu terlambat. Dengan demikian penundaan jarak kawin pertama pascapartum merupakan kegagalan reproduksi yang bersifat sementara. Ini sesuai dengan pendapat Carter et al. (1980); Partodihardjo (1992) dan Hafez (2000) bahwa untuk mendapatkan $\mathrm{S} / \mathrm{C}$ yang rendah tidak perlu menunda kawin pertama pascpartum, karena kegagaian menjadi bunting juga disebabkan oleh tidak bertemunya ovum dan spermatozoa di tempat fertilisasi sehingga tidak terjadi pembuahan. Demikian juga dengan interval kawin pertama pascapartum yang lebih pendek akan membutuhkan inseminasi yang lebih banyak untuk bunting.

Rataan angka perkawinan per kebuntingan pada penelitian ini lebih rendah dari yang dilaporkan oleh Kumar (1982) yaitu 2,36, dan hampir sama dengan dengan yang dilaporkan oleh Parehk dan Touchberry (1982) bahwa angka perkawinan per kebuntingan adalah 1,43. Rataan angka perkawinan per kebuntingan pada penelitian ini merupakan angka yang optimal karena termasuk dalam kisaran 1,3 - 1,7 (Dirjen Peternakan, 1979). Diperkuat oleh Payne (1970) menyatakan bahwa dalam suatu usaha peternakan yang memuaskan dan memberikan 
hasil yang baik dalam reproduksi maka $\mathrm{S} / \mathrm{C}$ harus diusahakan berkisar antara 1,3-1,6. Tinggi rendahnya angka perkawinan per kebuntingan, disamping karena jarak kawin pertama pascapartum juga disebabkan oleh kesuburan betina dan fertilitas semen beku yang digunakan dalam program IB.

Pengamatan berahi dan kawin pertama pascapartum pada peternakan rakyat perlu dilakukan untuk mendapatkan hasil IB yang maksimal. Hal ini disebabkan faktor biologis dan manajemen selalu bersama-sama dalam suatu periode reproduksi. Untuk itu perlu dilakukan pengamatan yang intensif dan tatalaksana perkawinan yang teratur, karena walaupun kondisi sapi sudah baik tetapi tatalaksana tidak teratur, maka performan reproduksi tetap rendah. Menurutnya Oltenacu et al. (1983) berpendapat bahwa kondisi alat reproduksi pada awal pascapartum merupakan faktor biologi yang berhubungan dengan reproduksi berikutnya. Selanjutnya angka perkawinan per kebuntingan mempunyai korelasi dengan calving interval, hal ini berkaitan dengan waktu yang dibutuhkan untuk menjadi bunting. Ini berarti semakin banyak kawin ulang (S/C), maka semakin panjang calving interval dan jumlah anak yang lahir akan rendah.

Berdasarkan perbahasan di atas dapat disimpulkan bahwa jarak jarak kawin pertama pascapartum untuk perlakuan B (90 hari pascapartum) merupakan yang terbaik dengan rataan angka perkawinan per kebuntingan (S/C) adalah 1,49. Secara keseluruhan dari hasil penelitian ini dapat disimpulkan bahwa perlakuan B merupakan yang terbaik, yang ditandai dengan tingginya angka kebuntingan (CR) dan rendahnya angka perkawinan per kebuntingan (S/C).

\section{Kesimpulan dan Saran}

\section{Kesimpulan}

1. Jarak kawin pertama pascapartum tidak berbeda nyata terhadap angka kebuntingan (CR) dan angka perkawinan per kebuntingan (S/C), Terdapat variasi pada angka kebuntingan dan angka perkawinan per kebuntingan dengan jarak kawin pertama pascapartum yang berbeda.
2. Angka kebuntingan yang tertinggi yaitu $61,25 \%$ dan angka perkawinan per kebuntingan yang terendah yaitu 1.49 didapatkan pada perlakuan $\mathrm{B}$ dan merupakan jarak kawin pertama yang terbaik.

\section{Saran}

Perlu pengawasan terhadap tatalaksana reproduksi untuk meningkatkan kesuburan ternak sapi betina dan dapat memperpendek calving interval atau jarak beranak pada ternak sapi.

\section{Daftar Pustaka}

Abeygunawardena, H., C. Mya Sein, and L. W. B. Epakanda. 1995. Status of the Artificial Insemination Program, Success Rate and Factor Affecting Fertility of Artificially Bred Cattle. Sri Lanka Vet. J. 42:25 26.

Alexander, P. A. B. D., H. Abeygunawardena, B. M. H. O. Perera, and I. S. Abeygunawardena. 1997. Current Status and Factor Affecting the Success of Artificial Insemination in Small Holder Farm in the Mid Country Wet Zone of Sri Lanka Tropical. Agric. Research. 9: 204 206.

Alexander, P. A. B. D., H. Abeygunawardena., B. M. H. O, Perera, and I. S, Abeygunawaedena. 1998. Reproduction Performance and Factor Affecting the Success Rate of Artificial Insemination of Cattle in Up-Country Multiple Farm of Sri Lanka Tropical.Agric. Research . 10 :356 371.

Bearden, H. J. and J. W. Fuguay. 1980. Applied Animal Reproduction. Reston Pub Co. Inc., A Prentice Hall. Co. Reston. Virginia.

Britt, J. H. 1975. Early Postpartum Breeding in Dairy Cow. J. Dairy Sci. 58: 266-271.

Carter, M. L., D. J. Dierschke, J. J. Rutledge, and E. R. Hauser. 1980. Effect of Gonadotropin Releasing Hormone and Calf Removing on Pituitary Ovarium functioned Reproductive Performance in Postpartum BeefCow. J.Anim. Sci. 51:903 910.

Hafez, E. S. E, 2000. Reproduction in Farm Animals Sixth Ed. Lea and Febiger. Philadelphia. 
Kumar, S. 1982. Source of Variation in Reproductive Traits of Hariana and Tharparkar cows. Indian. J Anim. Sci. 52 : 203209.

Laster, D. B., H. D. Glimp and K. E. Gregory. 1973. Effect of Early Weanning on PostPartum Reproduction of Cows. J. Anim. Sci. 36:734 740 .

Morrow, D. A., S. J. Roberts, K. McEnteeand H. G. Gray. 1969, Postpartum Ovarian Activity and Uterine Involution in Dairy Cattle. J. Am. Vet. Med. Ass. 149: 1596 1609.

Oltenacu, P. A, J. H. Britt, R. K. and R.W. Mellenberger. 1983. Relationship Among Type of Parturation, Type of Discharge from Genital Tract, Involution of Cervic and asaubsequent Reproductive Performance in Holstein Cows. J. Dairy Sci.36:612 619 .

Partodihardjo, S. 1992. Ilmu Reproduksi Hewan. Cetakan ke 2. Mutiara Sumber Widya Jakarta.

Partiman, A. 1982. Problem Reproduksi pada Ruminansia Besar di Yogyakarta. Dalam
Proceedings Pertemuan Ilmiah Ruminansia Besar. Pusat Penelitian dan Pengembangan Peternakan (BPPP). Departemen Pertanian Bogor.

Payne, W. J. A. 1970. Cattle Production in the Tropics. Logman Group Ltd. London.

Parehk, H. K. B. and R. W. Touchberry, 1982. Comparative Performance of Cross-breed and Contemporary Pure Breed Dairy Cattle 2. Cows Calving Record of Dry Period. Indian J. Anim. Sci. $54: 210215$.

Spicer, L. J., K. Leung, E. M. Convey, J. Gunther, R. E. Short and H. A. Tucker. 1986. An Ovulation in Postpartum Suckled Beef Cows. 1. Association Among Size and Number of Ovarian Follicles, Uterine Involution and Hormone in Serume and Follicular Fluid. J. Anim. Sci. 62:734 740.

Steel R. G. D. dan J. H. Torrie. 1989. Prinsip dan Prosedur Statistika Suatu Pendekatan Biometrik. Diterjemahkan oleh Sumatri. PenerbitPT. Gramedia. Jakarta.

West. G. P. 1975. Block's Veterinary Dictionary. 11 th Ed .Adam \& Charles Black London. 